\title{
Resilience: A Coping Strategy for Professional Women Dealing with Workplace Bullying
}

\author{
Vanessa M Gattis* \\ Department of International Psychology, USA
}

*Corresponding author: Vanessa M Gattis, Adjunct Assistant Professor, Department of International Psychology, USA.

\section{Abstract}

Workplace bullying, the repeated and regular act of harassing, offending, socially excluding someone, or negatively affecting someone's work has been recognized as a serious threat to the health and well-being of employees. This study explored resilience, the successful adaptation despite challenging and threatening circumstances, as a coping strategy to help improve the physical and mental health of professional women who have experienced workplace bullying.

The central research question was, how does perceived resilience, when used as a coping strategy, help with the physical and mental health stressors while helping to improve the overall well-being of professional women who were or have experienced workplace bullying? Four major themes emerged: Negative Experiences, Consequences of Bullying, Impact on Health, and Support Systems. The results suggested that the participants believed they were targeted because of race, gender, and age. Workplace bullying does have negative health consequences; however, various support systems greatly increased their resilience.

Keywords: Workplace bullying; Resilience; Coping strategy; Health; Well-being

\section{Introduction}

One of the fastest growing problems in the American workforce is workplace bullying [1]. Workplace bullying is the repeated and regular act of harassing, offending, socially excluding someone, or negatively affecting someone's work over a period and has been recognized as a serious threat to the health and well-being of employees [2]. The negative behavior manifests itself in multiple ways including direct (physical and verbal), indirect (psychological and relational), work-related (withholding information), personrelated (socially excluding), and physical intimidation (finger pointing) [3]. According to Keashly \& Harvey [4], a significant number of workers have been persistently exposed to abusive behavior in the workplace. In fact, research indicated that in both Europe and North America, $10 \%$ to $15 \%$ of the workforce have been exposed to workplace bullying [5,6]. A survey conducted by the Workplace Bullying Institute [7] on U.S. workers estimated that approximately $27 \%$ of U.S. workers have experienced some level of workplace bullying.

Introduced as a workforce phenomenon in the 1970's, workplace bullying emerged as a complex issue that was often misunderstood [8]. Research scholars have had a growing interest in the phenomenon and over the past 20 years, they have sought to gain a better understanding while attempting to find strategies to combat the issue $[9,10]$. From an organizational perspective, workplace bullying can pose a huge problem for both the organization and the employees, as the negative consequences can significantly diminish overall well-being, employee morale, productivity [11,12], and increase turnover, while incurring significant financial loss and legal cost to the organization [13-16]. For workers, workplace bullying can lead to physical and mental stresses that can diminish the effectiveness of the employees. For women, workplace bullying occurs more frequently compared to men [17] and is one of the most troublesome issues that they face in the workplace [1].

Workplace bullying literature supported the fact that women were bullied at higher rates and more often compared to men [7]. According to a statistical survey conducted by the [7], women made up $60 \%$ of the bullied targets. Additionally, of the people who are targeted, $69 \%$ of the perpetrators were men. Research also showed that women who were targeted, experienced increased health 
consequences, which resulted in a significant amount of time away from the workplace posited that women were more vulnerable to bullying behavior because they were considered the weaker sex, and it was recognized in organizations as acceptable behavior $[17,18]$.

Women who continue to encounter difficulties in the workforce, their work performance, as well as their mental health, are greatly impacted [19]. Additionally, Lewis S [17], argued that women who experienced bullying in the workplace greatly affected their physical and mental health, resulting in well-documented psychological effects consistent with stress, anxiety post-traumatic stress disorder, and depression [20-26]. Unfortunately, the literature clearly lacked enough methods that helped professional women cope with the effects of workplace bullying. Mikkelsen EG, et al. [27] argued that greater understanding was needed to fully grasp the extent and magnitude of workplace bullying; while the current research suggested that using resilience might help protect workers from the negative health effects of those who were or have experienced workplace bullying [28,29].

A review of the literature lacked enough studies that explored the physical and mental health consequences of workplace bullying in professional women $[1,30]$. Resilience, which is the process or capacity to successfully overcome challenges and threatening circumstances (Masten, Best \& Garmezy, 1990), when used as a coping strategy, may help improve the overall well-being of professional women who have or are experiencing workplace bullying [27-30]. Researchers argued that greater understanding is needed to fully grasp the extent and magnitude of workplace bullying; while the current research suggested that using resilience may help protect workers from the negative health effects of those who are or have experienced workplace bullying [27-30]. This study looked at perceived resilience as a coping strategy to help facilitate increased well-being of professional women within an organizational environment who are dealing with workplace bullying.

\section{Workplace Bullying and well-being}

In 1990, Leymann studied bullying behaviors on the playground and drew similar conclusions of the negative behaviors experienced in the workplace. This brought much need attention to workplace bullying. Since then, several researchers have investigated workplace bullying and have created their own definition of the phenomenon [31,32] Despite the various definitions of workplace bullying, the common denominator was that the targeted individual must have been exposed to the negative behavior frequently and over a period of time, typically over a 6-month period [33-35].

Workplace bullying behaviors can range from harassment, offending or socially excluding individuals in the workplace [36], to an individual's professional status being undermined [3,37]. The behavior can also negatively affect a person's ability to accomplish his or her job [38,39] determined that the adverse effects of workplace bullying could result in anxiety, stress, burnout, and depression. Workplace bullying can also jeopardize the overall health and well-being of individuals, and if not dealt with properly, not only is an individual's health diminished, but his or her work productivity decreases, which can incur significant recruiting and retention costs to organizations [12,26][40-42]. The literature suggested that women were more susceptible to workplace bullying resulting in them either leaving their jobs or suffering significant challenges to their physical and mental health [12].

Considering the limited strategies and/or tools available to combat this organizational issue, there is still a gap in the literature that considered effective resources to help professional women cope and deal with the phenomenon. In fact, throughout the literature, resilience is hardly mentioned as an available tool to help cope with workplace bullying [28-31]. Research on resilience showed that it can empower people to overcome physical and mental stressors, become more confident, and show a stronger sense of self in the workplace $[20,43]$.

\section{Influence of resilience on workplace bullying}

Professional women who are resilient when dealing with negative workplace behaviors, can increase their overall wellbeing and work performance within an organization. When used as a coping strategy, resilience literature suggested that it could be "synonymous with reduced vulnerability" [44] Additionally, resilience has also been identified as a significant contributor to improved health, cognitive processes, and coping skills $[31,43]$. Recent studies posited that using resilience as a personal resource might help protect workers from the negative health effects of workplace bullying [29,30].

\section{The current study}

This research demonstrated that resilience could be used as a strategy to help professional women cope with the physical and mental health stressors associated with workplace bullying. Additionally, this study also showed that increased resilience could decrease worker turnover. This project built on those previous studies by examining professional women within the National Capital Region of Washington, DC, who reported that they had experienced workplace bullying over a 6-month period or more.

This qualitative single-case study explored how the influence of resilience, when used as a coping strategy, could help professional women overcome the physical and mental health stressors associated with workplace bullying, while helping to improve their overall well-being. Additionally, it focused on three specific areas of inquiry:

1. whether professional women perceived that they were targets of workplace bullying based on demographics (age, gender) and culture (race, ethnicity);

2. if perceived resilience was considered an effective coping strategy for professional women's overall well-being when exposed to workplace bullying. 
3. if perceived resilience helped to improve their overall physical and mental health levels as a result of workplace bullying.

\section{Method}

A total of 10 professional women who were or have experienced workplace bullying described their experiences and the role of resilience as a coping strategy for their overall well- being was the central focus of this case study. The mean age of all participants was 49.5 years, while the average years for professional work experience was 25.3 years. The professional educational level distribution was as follows: bachelor's degree (100\%), master's degree (40\%), and a Ph.D. degree (10\%). The ethnicity distribution was as follows: Asian (10\%), Black (50\%), White (20\%), and Hispanic (20\%). A criterion was set that each professional woman had to be currently or have experienced workplace bullying for at least six months.

The design for this study used open-ended interviews, researcher notes, the SF12v2, Your Health and Well-Being Survey [45] and the Resilience at Work (R@W) Scale [46]. Using an open-ended interview with each participant provided a deeper understanding regarding the onset of the phenomenon of workplace bullying and what led to the unwanted behavior, while the researcher notes captured information taken during the interview sessions. Additionally, the use of the Resilience at Work (R@W) Scale [46] and the SF12v2, Your Health and WellBeing Survey [45] delved more in-depth into the investigation of resilience, when used as a coping strategy, and whether it aided in decreased physical and mental health levels, while improving the overall well-being of the professional women.

The Resilience at Work (R@W) Scale is a 20-item self-reported psychometric instrument developed by [46] that measures individual workplace resilience. The scale is a tool designed for individual workers who experience stress-related difficulties in the workplace [47] The RAW Scale is a validated tool that specifically measures employee resilience at work focusing on everyday workplace behaviors rather than personality. According to the developers, the emphasis for the scale is placed on building on the individual worker's strengths rather than focusing on coping strategies. Further, the SF12v2, Your Health and Well-Being Survey [45] is a 12-item instrument that was developed to measure the health-related quality of life of individuals. A subset of the SF36 health-related quality of life measurement, the SF-12v2 was released in 2002; the instrument's focus is on two distinct overall physical and mental concepts: Physical Component Summary (PCS) and the Mental Component Summary (MCS); these were examined and validated worldwide (Fleishman et al., 2010).

\section{Discussion}

This article assessed the influence of resilience, when used as a coping strategy, how it helped professional women overcome the physical and mental health stressors associated with workplace bullying. The researcher further assessed how resilience would be used to help improve the overall well-being of professional women, which offered the means to answer the following major research question: How does perceived resilience, when used as a coping strategy, help with the physical and mental health stressors while helping to improve the overall well-being of professional women who were or have experienced workplace bullying?

Demographic details were collected during the interview that included the gender, as well as the position of the bully. Figure 1 shows that females made up $53 \%$ of the bullies, while $47 \%$ were male bullies. In addition, Figure 2 highlights that $72 \%$ of the professional women who participated in the study were bullied by their immediate supervisors, $21 \%$ were bullied by a peer, and $7 \%$ were bullied by a subordinate respectively. Of note was the fact that two of the 10 professional women who participated in the study were each bullied by two male supervisors, and one of the 10 professional women was bullied by two female supervisors. Additionally, one of the 10 professional women was bullied by two male peers and one female subordinate.
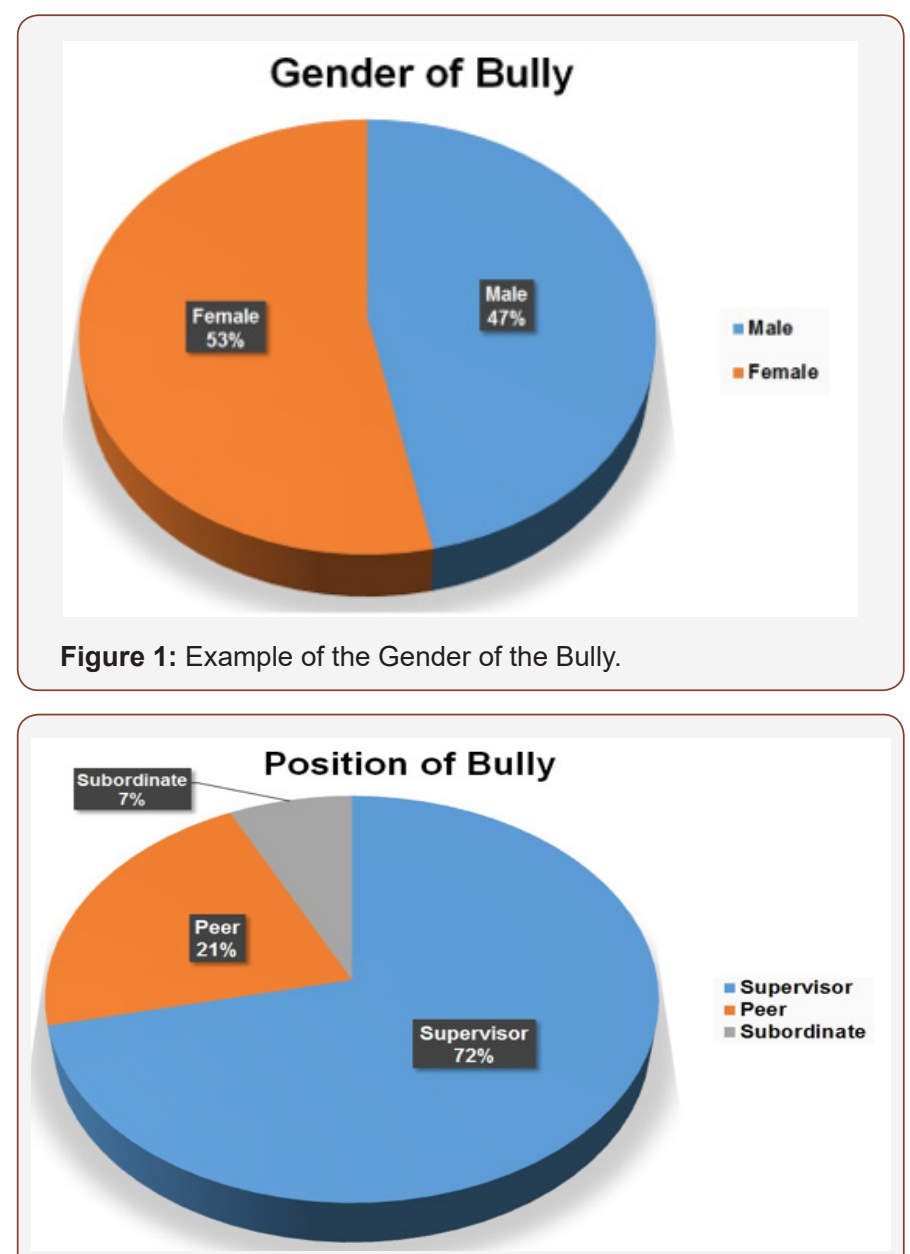

Figure 2: Example of the Position of Bully.

This study utilized the six-step process, as highlighted by $[48,49]$ for conducting thematic analysis to gain an understanding of the 10 participants' experiences and to present the data collection in an informative and accurate manner [50]. After coding and categorizing the data in terms of the categories per research question, codes from the responses, and then the formed themes, the researcher apportioned the data into appropriate themes. The researcher used an inductive coding process to examine all the data available directly. The data analysis matrix, as shown in Table 
1, provides the relationship between the constructs, the interview questions, the researcher notes, the structured questionnaires, and the associated themes for this study. This method was particularly useful and meaningful in coding the individual professional women's patterns, while comparing, contrasting, and summarizing all the women. The themes that derived from the coding process used to analyze the interviews with the professional women were also used through analysis of the two survey instruments and the researcher notes. Four themes emerged from this study.

Table 1: Results of the Data Analysis Matrix.

\begin{tabular}{|c|c|c|}
\hline $\begin{array}{l}\text { Constructs/ } \\
\text { Categories }\end{array}$ & Core Themes & $\begin{array}{c}\text { Interview } \\
\text { Question(s) and } \\
\text { Survey Instrument }\end{array}$ \\
\hline $\begin{array}{l}\text { Workplace } \\
\text { Bullying }\end{array}$ & $\begin{array}{l}\text { 1. Negative Experiences } \\
\text { 2. Consequences of Bullying }\end{array}$ & $1-7,10,13,15$ \\
\hline Physical Health & 3. Impact on Health & 4,11-12; SF12v2 \\
\hline Mental Health & 3. Impact on Health & 4, 11-12; SF12v2 \\
\hline Overall well-being & & 9 \\
\hline Resilience & 4. Support Systems & $\begin{array}{l}\text { 8-9, 14-15; RAW } \\
\text { Scale }\end{array}$ \\
\hline
\end{tabular}

A. The themes included: experiencing negative actions and treatments

B. experiencing the consequences of bullying

C. having an impact on health, and

D. support systems.

The first research question asked how professional women perceived that they have been targets of workplace bullying based on demographics and culture. Seven of the 10 participants believed that gender, age, and race were indeed the causes of the workplace bullying that they experienced. In this category, two major themes were formed. Table 2 contains the findings from the thematic analysis of the interviews, while Table 3 contains the complete breakdown of the themes per participant. The first major theme that emerged was the negative experiences of the participants from the workplace bullying that they had to endure. In this theme, most of the participants highlighted the verbal abuses and maltreatments that they faced in the workplace.

Table 2: Breakdown of Interview Themes Addressing $R Q_{1}$.

\begin{tabular}{|c|c|c|}
\hline Major Themes and Sub-Themes & Number of Occurrences & Percentage of Occurrences \\
\hline Major Theme 1: Experiencing negative actions and treatments & 10 & $100 \%$ \\
\hline Subtheme 1: Being humiliated & 7 & $50 \%$ \\
\hline Subtheme 2: Feeling embarrassed & 5 & $50 \%$ \\
\hline Subtheme 3: Disparaging remarks & 5 & $40 \%$ \\
\hline Subtheme 4: Being criticized & 4 & $40 \%$ \\
\hline Subtheme 5: Receiving bad evaluation and no promotion & 3 & $30 \%$ \\
\hline Subtheme 6: Feeling belittled & 3 & $30 \%$ \\
\hline Subtheme 7: Feeling antagonized & 3 & $30 \%$ \\
\hline Subtheme 8: Being withheld of information & 3 & $30 \%$ \\
\hline Subtheme 9: No communication with coworkers & 2 & $20 \%$ \\
\hline Subtheme 10: Being yelled or screamed at & 2 & $20 \%$ \\
\hline Subtheme 11: Feeling threatened & 10 & $100 \%$ \\
\hline Major Theme 2: Experiencing the consequences of bullying & 6 & $60 \%$ \\
\hline Subtheme 1: Quit, fired, transferred & 4 & $40 \%$ \\
\hline Subtheme 2: Bullying has not stopped & & \\
\hline
\end{tabular}

Table 3: Breakdown of Themes Per Participant.

\begin{tabular}{|c|c|c|c|c|c|c|c|c|c|c|c|}
\hline $\mathbf{R Q}_{1}$ & $\mathrm{PW}_{1}$ & $\mathrm{PW}_{2}$ & $\mathrm{PW}_{3}$ & $\mathrm{PW}_{4}$ & $\mathrm{PW}_{5}$ & $\mathrm{PW}_{6}$ & $\mathrm{PW}_{7}$ & $\mathrm{PW}_{8}$ & $\mathrm{PW}_{9}$ & $\mathrm{PW}_{10}$ & Frequency \% \\
\hline Gender & & $\mathrm{X}$ & & & $\mathrm{X}$ & $\mathrm{X}$ & & $\mathrm{x}$ & $\mathrm{X}$ & $\mathrm{X}$ & $60 \%$ \\
\hline Age & $\mathrm{x}$ & & & & $\mathrm{X}$ & $\mathrm{X}$ & & $\mathrm{x}$ & $\mathrm{X}$ & & $50 \%$ \\
\hline Race & $\mathrm{X}$ & $\mathrm{X}$ & & & $\mathrm{x}$ & $\mathrm{x}$ & & $\mathrm{x}$ & $\mathrm{X}$ & $\mathrm{x}$ & $70 \%$ \\
\hline \multicolumn{12}{|c|}{ Major Theme 1: Experiencing negative actions and treatments } \\
\hline Being humiliated & $\mathrm{X}$ & & & $\mathrm{X}$ & $\mathrm{X}$ & $\mathrm{x}$ & & $\mathrm{x}$ & $\mathrm{X}$ & $\mathrm{x}$ & $70 \%$ \\
\hline Feeling belittled & $\mathrm{X}$ & & & & $\mathrm{X}$ & & & & & $\mathrm{X}$ & $30 \%$ \\
\hline Being yelled or screamed at & & $\mathrm{X}$ & & $\mathrm{X}$ & & & & & & & $20 \%$ \\
\hline Feeling embarrassed & $\mathrm{X}$ & $\mathrm{X}$ & & & $\mathrm{X}$ & & & $\mathrm{x}$ & & $\mathrm{X}$ & $50 \%$ \\
\hline Being criticized & & & & & $\mathrm{x}$ & & $\mathrm{X}$ & & $\mathrm{x}$ & $\mathrm{X}$ & $40 \%$ \\
\hline Feeling threatened & & $\mathrm{X}$ & $\mathrm{X}$ & & & & & & & & $20 \%$ \\
\hline Feeling antagonized & & & & $\mathrm{X}$ & & $\mathrm{X}$ & & & & $\mathrm{x}$ & $30 \%$ \\
\hline
\end{tabular}




\begin{tabular}{|c|c|c|c|c|c|c|c|c|c|c|c|}
\hline Being withheld of information & & & & & $\mathrm{X}$ & & $\mathrm{X}$ & $\mathrm{X}$ & & & $30 \%$ \\
\hline $\begin{array}{l}\text { Receiving bad evaluation and } \\
\text { no promotion }\end{array}$ & $\mathrm{X}$ & & & & $\mathrm{X}$ & $X$ & & & $\mathrm{X}$ & & $40 \%$ \\
\hline $\begin{array}{l}\text { No communication with } \\
\text { coworkers }\end{array}$ & & $\mathrm{x}$ & & & $\mathrm{X}$ & $\mathrm{X}$ & & & & & $30 \%$ \\
\hline Disparaging remarks & $\mathrm{X}$ & & & & $\mathrm{X}$ & & $\mathrm{X}$ & $\mathrm{X}$ & & $\mathrm{X}$ & $50 \%$ \\
\hline \multicolumn{12}{|c|}{ Major Theme 2: Experiencing the consequences of bullying } \\
\hline \multicolumn{12}{|c|}{ Experiencing the consequences of bullying } \\
\hline Quit / fired / transferred & & & $\mathrm{X}$ & $\mathrm{X}$ & & & $\mathrm{X}$ & $\mathrm{X}$ & $\mathrm{X}$ & $\mathrm{X}$ & $60 \%$ \\
\hline Bullying has not stopped & $\mathrm{X}$ & $\mathrm{X}$ & & & $\mathrm{X}$ & $\mathrm{X}$ & & & & & $40 \%$ \\
\hline
\end{tabular}

The major theme had 11 underlying sub-themes directly related to the negative experiences of the participants. The first sub-theme of the negative experiences was that the participants were humiliated. This was stated by seven of the 10 participants. According to $\mathrm{PW}_{1}$, her boss would humiliate her an open place where everyone in the office could witness the act or hear her boss' punitive words: Yes. It didn't matter what the ... I mean most of our meetings were out in the open anyway because we are in cubicles land so anybody who is close by could hear.

The second sub-theme that followed was being a target and experiencing the feeling of embarrassment. This was shared by 5 of the 10 participants or $50 \%$ of the sample. $\mathrm{PW}_{2}$ shared the many derogatory remarks made her feel unwanted, not needed, and embarrassed in front of those who should respect her inside her workplace:

In my office, I've had the individual stand over me with clenched fist, yelled, and interrupted constantly during staff meetings. Wasn't listening to any input, tried to embarrass in public, put me into a condition where I am basically just an administrator, paid assistant, not allowing to do my job, tell me that I don't have a place in that office. I get told that there's not a need for a civilian in my office. That's day in and day out.

The third sub-theme that followed was being targeted through the disparaging remarks. The experience was stated by another five participants. $\mathrm{PW}_{5}$ simply shared the usual comments and remarks she found offending:

I think that age absolutely played a role in it because they are constantly asking me, "When are you going to retire? Are you going to retire?" I've been told I was old as dirt, or, "Ask PW $_{5}$, she's been here since the beginning of time." Absolutely, I think age played a role in it.

The fourth sub-theme that emerged was being criticized. This was shared by four of the 10 participants or $40 \%$ of the sample. $\mathrm{PW}_{7}$ believed that neither gender, race, nor age were factors for workplace bullying. However, constant criticisms were received in her everyday work and activities. Her peers would regularly question her abilities to perform her tasks and had even gone to the extent of questioning her to the upper management:

Some of the acts were constantly questioning my ability to do my work. Constantly going to the president or the vice president of the company who was her direct supervisor to question my ability to do my work. We were in meetings it seems like every other week, because of something that she said to me or something that I said to her that she did not like, but she would go to the supervisor and, of course, she would tell on me that I did something or I said something that she didn't think was appropriate. We ended up in these meetings sometimes two, three hours long, which again, affects my productivity.

The fifth subtheme that emerged was being targeted by receiving bad evaluations and no promotion. The theme received four occurrences out of the 10 participants. $\mathrm{PW}_{9}$ reached the point of being let go because of the negative evaluations and grades submitted about her. She believed that there were many different individuals and supervisors behind this act: She was already, it seemed to me, aware of what was going on by the supervisor who was bullying me and seemed to almost be in support of what the supervisor was doing. By the time this got to HR, it was almost already a lost cause. It had been going on for a long time at that point. I probably took too long to complain about it. Too much had happened regarding the write ups, about me having health issues, regarding me going to the doctor, and just trying to seek out help, I allowed it to go on too long.

The sixth subtheme included feeling belittled, which three participants or $30 \%$ admitted to feeling. $\mathrm{PW}_{5}$ shared the different belittling comments and remarks that she normally received from her boss. She added that when she would open up about feeling offended by the comments, the normal response from everyone was that she is just being "sensitive": Early on it was subtle. It would just be the snide remarks about me personally, things like, "That sounds like someone from Somewhere, Kentucky," when I would say something or make a comment. My response normally would be, "Well, it should. I am from Somewhere, Kentucky." Or comments like, "Those are trailer trash people. Oh, but I'm not talking about you, $\mathrm{PW}_{5}$." Generally, I would just ignore comments like that. when I would suggest, or suggest another way of looking at a possible solution as a course of action, I would be criticized for that and told that I always continue to chime in. It was somewhat subtle. Some people would say, "Probably you're overly sensitive."

The seventh subtheme was feeling antagonized; this was again stated by three of the 10 participants or $30 \%$. $\mathrm{PW}_{4}$ believed that workplace bullying was not an effect of her gender, race, and age. However, constant resentment and dislike was still experienced. 
The eighth subtheme that followed was being withheld of information, which was shared by $30 \%$ of the participants. $\mathrm{PW}_{5}$ shared how she was withheld from knowing about important work-related knowledge and information. She described how she was also not allowed to attend meetings and other work- related functions anymore. In addition, her boss would also restrain her from having access to significant data for her projects.

Another experience, subtheme 9, was having no communication with coworkers. This was again stated by three participants. PW explained that the reason of her lack of communication with her coworkers was the fact that no one could talk or interact with her. She added that there were individuals from the upper management who would even manipulate and harass the other coworkers if they talked to her.

The tenth subtheme that followed was being yelled or screamed at, which was shared by two participants. $\mathrm{PW}_{2}$ admitted that she had no communication with her coworkers, as they would rather keep a low profile than be harassed and bullied when they speak to her: Most don't. Some just keep a low profile. They know what's going on, but they just keep a low profile."

Finally, the eleventh subtheme that followed was feeling threatened as shared by two participants. $\mathrm{PW}_{3}$ received threats from a certain individual. She believed that the said individual felt intimidated by her and her staff's ability, thus the negative reaction from the person: It was mainly threatening from this individual. Her way was the only way and my advice and my staff's advice was thoroughly dismissed because she was the Waiver Attorney and the smartest person in the room. It affected the higher district. It wasn't just me, but it was my staff and pretty much everyone that she dealt with.

The second major theme that emerged was experiencing the consequences of bullying, which had two underlying themes. The sub-themes related were the consequences of quitting, being fired, and transferring. The other sub-theme was that the bullying has not stopped. The first subtheme that emerged was quitting, being fired, and transferring. The theme received six occurrences. $\mathrm{PW}_{9}$ explained how the bad evaluations and feedback about her eventually led to her being let go. She described her case as a "lost cause," where the human resources even had to escort her out of the building upon believing all the negative comments and reports about her: She was already, it seemed to me, aware of what was going on by the supervisor who was bullying me and seemed to almost be in support of what the supervisor was doing. By the time this got to HR, it was almost already a lost cause. It had been going on for a long time at that point. I probably took too long to complain about it. Too much had happened regarding the write ups, regarding me having health issues, about me going to the doctor, and just trying to seek out help, I allowed it to go on too long. By the time, it had gotten to Human Resources, they had pretty much built a case against me as though I'm the problem. Human Resources called me in one day and said, "We're letting you go today," and I'm asking, "Well, why am I being fired." "Oh, we don't have to give you a reason. You just need to leave." They had security escort me out of the building.

The second subtheme that followed was that the experience that the bullying had not stopped, which received four occurrences or $40 \%$ of the participants. $\mathrm{PW}_{5}$ explained that the workplace bullying had not stopped, and she had even been assigned to another office until the situation had been addressed and fixed by the management. Up until present, she was still being treated unfairly and important information about her job was still being withheld from her: No, they haven't stopped. Currently, I've been detailed for another office until this can get worked out. For instance, the new Army regulation came out on the Army program. Do you think anyone bothered to notify me or send that to me? No, someone in the field contacted me and said, "Hey, the new regulation is out." My supervisor did not send it to me. Someone had to send me it. I saw all the people that my supervisor sent it to. A colleague got it, but he did not send it to me.

When the final report was published, my head supervisor got it and the briefings occurred in the building, I never received any information on the draft that the head supervisor got. The only way I got the draft was because someone from the field told me about it. One would think me and the office that work the task, would have the information shared with me. It was not. Key information regarding my job and my ability to do my job has been kept from me. It's kept from me even to this day.

Table 4: Breakdown of Interview Themes Addressing $R Q_{2}$.

\begin{tabular}{|c|c|c|}
\hline \multicolumn{1}{|c|}{ Major Themes and Subthemes } & Number of Occurrences & Percentage of Occurrences \\
\hline Theme 1: Talking with others & 10 & $100 \%$ \\
\hline \multicolumn{2}{|c|}{ Major Theme 3: Having an impact on Health } \\
\hline Theme 2: Relying heavily on Faith & 9 & $70 \%$ \\
\hline Subtheme 1: Being stressed & 8 & $90 \%$ \\
\hline Subtheme 2: Having anxiety & 5 & $50 \%$ \\
\hline Subtheme 3: Experiencing lack of sleep & 4 & $40 \%$ \\
\hline Subtheme 4: Experiencing headaches and panic attacks & 4 & $40 \%$ \\
\hline Subtheme 5: Affecting concentration & 4 & $40 \%$ \\
\hline Subtheme 6: Affecting confidence & 3 & $30 \%$ \\
\hline Subtheme 7: Having depression & & \\
\hline
\end{tabular}


Table 5: Breakdown of Themes Per Participant.

\begin{tabular}{|c|c|c|c|c|c|c|c|c|c|c|c|}
\hline & $\mathrm{PW}_{1}$ & $\mathrm{PW}_{2}$ & $\mathrm{PW}_{3}$ & $\mathrm{PW}_{4}$ & $\mathrm{PW}_{5}$ & $\mathrm{PW}_{6}$ & $\mathrm{PW}_{7}$ & $\mathrm{PW}_{8}$ & $\mathrm{PW}_{9}$ & $\mathrm{PW}_{10}$ & Frequency $\%$ \\
\hline \multicolumn{12}{|c|}{$\begin{array}{l}\text { RQ\#2: Why is perceived resilience considered an effective coping strategy for a professional women's overall well- being when exposed to workplace } \\
\text { bullying? }\end{array}$} \\
\hline Relying heavily on Faith & $\mathrm{x}$ & $\mathrm{x}$ & & & $\mathrm{x}$ & $\mathrm{x}$ & $\mathrm{x}$ & $\mathrm{X}$ & $\mathrm{x}$ & & $70 \%$ \\
\hline Talking with others & $\mathrm{x}$ & $\mathrm{X}$ & $\mathrm{X}$ & & $\mathrm{x}$ & $\mathrm{x}$ & $\mathrm{x}$ & $\mathrm{X}$ & $\mathrm{x}$ & $\mathrm{x}$ & $100 \%$ \\
\hline \multicolumn{12}{|c|}{ Major Theme 3: Having an impact on Health } \\
\hline Impact on Health & $\mathrm{x}$ & & & $\mathrm{x}$ & $\mathrm{x}$ & $\mathrm{x}$ & & $\mathrm{X}$ & $\mathrm{x}$ & $\mathrm{x}$ & $70 \%$ \\
\hline Experiencing lack of sleep & & & & $\mathrm{x}$ & $\mathrm{x}$ & $\mathrm{x}$ & & & $\mathrm{x}$ & $\mathrm{x}$ & $50 \%$ \\
\hline $\begin{array}{l}\text { Experiencing headaches and } \\
\text { panic attacks }\end{array}$ & & & & & $\mathrm{x}$ & $\mathrm{x}$ & $\mathrm{x}$ & & & $\mathrm{X}$ & $40 \%$ \\
\hline Having anxiety & $\mathrm{x}$ & $\mathrm{X}$ & & $\mathrm{X}$ & $\mathrm{X}$ & $\mathrm{X}$ & & $\mathrm{X}$ & $\mathrm{x}$ & $\mathrm{x}$ & $80 \%$ \\
\hline Having depression & $\mathrm{X}$ & $\mathrm{X}$ & & & & & & & & $\mathrm{x}$ & $30 \%$ \\
\hline Being stressed & $\mathrm{x}$ & $\mathrm{X}$ & $\mathrm{x}$ & & $\mathrm{x}$ & $\mathrm{x}$ & $\mathrm{x}$ & $\mathrm{X}$ & $\mathrm{x}$ & $\mathrm{x}$ & $90 \%$ \\
\hline Affecting concentration & & & & & $\mathrm{x}$ & & $\mathrm{x}$ & & $\mathrm{x}$ & $\mathrm{x}$ & $40 \%$ \\
\hline Affecting confidence & & $\mathrm{X}$ & & & $\mathrm{X}$ & & & $\mathrm{X}$ & & $\mathrm{X}$ & $40 \%$ \\
\hline
\end{tabular}

The second research question was the perception on why resilience was considered an effective coping strategy for a professional woman's overall well-being when exposed to workplace bullying. In this category, two themes emerged, with one major theme. Tables 4 contains the breakdown of the interviews, addressing the second research question; while Table 5 contains the themes based on the participants who experienced or shared them. For the participants, talking with others and relying heavily on faith resulted in their resilience while managing the workplace bullying. All ten participants indicated that talking with others was the most effective method, while seven indicated that their faith helped them greatly.

According to the women professionals, these methods guided them in managing the workplace bullying and proved that faith and having a support system can be used to cope with the adverse effects of bullying. The first theme that emerged, based on the second research question was talking with others, which received all 10 occurrences. $\mathrm{PW}_{3}$ 's resilience allowed her to move past her negative experiences. She shared how having a strong network of family and friends allowed her to deal with the negativities of her professional life:

Oh, it's has. I think a lot of it has to do with my personality and adaptability. Having a very strong network of people that I can go to and when issues were going on, I kept talking about it to people and say, "Hey, I've got a problem and I haven't dealt with this in my entire career, I need some advice." I had Assistant Managers that I was able to go and talk to and give me some recommendations. It clearly helped me. I could go home at night and check with my husband what I needed to, but I would say with my case, it helped.

The second theme that followed was relying heavily on faith, which aided and added their resilience in managing bullying. $\mathrm{PW}_{5}$ simply explained that a positive lifestyle mainly through her faith allowed her to forgive the people who bullied and did her wrong. Although in the researcher's notes, it was found that she was greatly affected by the workplace bullying, she explained that her resilience allowed her to move forward with a positive attitude and view about life:

It allows me to try to stay healthy, meaning with doing my walking, doing positive thinking, praying, asking God to give me gratitude and forgiveness for people that I don't understand why they treat me this way. I believe that because I've always tried to live a healthy lifestyle and a resilient lifestyle, that it's allowed me to withstand this. Being around positive people and encouraging people have also been very, very helpful.

Knowing that I'm doing the right thing by standing up for myself, which I think is a good resiliency practice. I could continue just to sit here and allow that to happen, and it would just be worse and worse and worse until they ran me down and got me to retire or take a job somewhere else.

The third major theme that emerged was that the workplace bullying had an impact on the health of the 10 participants. The major theme had seven underlying themes, all related to the effects of workplace bullying when participants had not realized their perceived resilience. The impact on health shared were all based on the firsthand experiences of the women, as they endured the daily bullying and verbal abuse at their workplace.

The first subtheme that emerged was the result of being stressed. The subtheme received nine occurrences. PW $_{6}$ admitted that because she had the tendency to internalize everything that happened to her, she developed major stress issues. In addition, stress derived from her inability to share her feelings and experiences with other people: Well, I think because I internalize a lot of it, and I did not really discuss it with people. Then when I did discuss it, I guess it made me upset about it because I'm talking about it. That's how that went. I guess that's it. I think because I internalize, my health went down. I guess I became susceptible to colds and things like that because my system was run down. I wasn't being healthy when I was here. I think that's how it affected my health: Blood pressure, asthma, heart palpitations, and anxiety. 
The second subtheme that followed was having anxiety attacks, which had eight occurrences. $\mathrm{PW}_{5}$ again shared her experience of anxiety, which reached to the point of not eating and sleeping properly. She furthered that up until today, she felt unsettled and alone: I have had some issues with my stomach. I cannot keep food in. I am very, very anxious. I have had problems sleeping. I have gone to the doctor about this and have had medication prescribed to help me sleep, but it has impacted my ability to concentrate. There's a feeling of vulnerability. I have headaches and just a loss of energy. I am healthy for my age, but I'm not as healthy as I was, even when I left my extended assignment because I'm unsettled. Even to this day, I'm going through something and I'm just unsettled. I feel like I don't have a home.

The third subtheme was experiencing a lack of sleep, which was indicated by 5 of the 10 participants. $\mathrm{PW}_{4}$ described her exposure to workplace bullying as the "worst job" she ever had. She experienced anxiety every time, every day she would go to work, and because she could not sleep properly: There was anxiety. Everyday walking in the door, it was a challenge to go to work, and so there was always anxiety every minute of the day. It was the worst job I've ever had. $\mathrm{PW}_{9}$ regarded anxiety and stress from the bullying as the causes of her lack of sleep and inability to perform and concentrate at work: As far health was concerned, I wasn't going to be able to control what my body was experiencing. As much as in my mind I was telling myself I'm not going to let this get to me and I'm going to bounce back from this. Me telling myself that is one thing, but my body was still responding in another way because it was still stressful and I'm still allowing myself to be in a stressful environment, so it took a little bit of time for my body to kind of unwind from all that had been going on in regards to losing sleep and being anxious and all that.

The fourth subtheme that followed was experiencing headaches and panic attacks. The subtheme received four occurrences. $\mathrm{PW}_{10}$ echoed the health problems she had faced from the workplace bullying. Initially, the stress and anxiety caught up with her and led to various health problems and issues: I ended up with some health problems that I don't know if ... I think the year of stress there caused. When I first got here, I ended up having a panic attack and when I went to the doctor, they said, "I definitely think you have anxiety," and as soon as I started talking about work, I just broke down and that's not a normal reaction. What took me to the hospital is these heart palpitations and abnormal heartbeat.

Table 6: BBreakdown of Interviews Themes Addressing $R Q_{3}$.

\begin{tabular}{|c|c|c|}
\hline Major Themes and Sub- Themes & Number of Occurrences & Percentage of Occurrences \\
\hline \multicolumn{3}{|c|}{ Major Theme 4: Support Systems } \\
\hline Subtheme 1: Having a strong faith & 7 & $70 \%$ \\
\hline Subtheme 2: Having family and friend support & 6 & $60 \%$ \\
\hline Subtheme 3: Seeking outside assistance and support & 6 & $60 \%$ \\
\hline Subtheme 4: Practicing proper exercise and diet & 5 & $50 \%$ \\
\hline Subtheme 5: Thinking positive & 5 & $50 \%$ \\
\hline Subtheme 6: Leaving the workplace & 2 & $20 \%$ \\
\hline
\end{tabular}

I was diagnosed with an arrhythmia and I believe it was all caused by a stress there. The not sleeping was also a physical result because literally I'd be up three in the morning reading emails, double checking work, or I'd be up at three in the morning in my head running through what he said to me, why did he say that, and does he have any justification for what he said. Just different ways to how am I going to handle the next day and that sort of thing. Lack of sleep also causes other health problems, so I think that was a problem, as well.

The fifth subtheme was that bullying affected the concentration of the four participants. $\mathrm{PW}_{9}$ shared that concentration was affected, as she was forced to miss work because she needed to see a doctor to manage the negative effects and impact of bullying: Yes, I did have to take off work. During the time my child was born, I was a little more unfamiliar with the phenomenon, and so like with many people my body was reacting to the stresses that I was experiencing. I was having a lot of trouble with sleeping. I was having anxiety, often anxiety attacks, and didn't want to be at work. It ended up resulting in me missing some work simply because I had to go to see a doctor for some of the affects, the bullying.

The sixth subtheme was that bullying affected the confidence of the four participants. $\mathrm{PW}_{2}$ simply shared that all her words and actions were affected, as she started to lose her confidence from the negative remarks and comments she would hear from her workmates and supervisors: Everything that I do. It impacts my confidence. It makes me less likely to provide input that I need to provide for the finished product, say the things I need to say based on my experience especially at my level. It has made me question myself sometimes and I don't think I provide answers that I could. That's what it's started to make me a little bit angry and questioning the system.

Finally, another three of the 10 participants experienced depression. $\mathrm{PW}_{2}$ admitted that she was formally diagnosed with depression: "[Formally diagnosed with] Depression, major depression is what it was." The third and final research question had one major theme and seven underlying sub- themes. The themes discuss the support systems that improved resilience and resulted to the overall physical and mental health levels of the participants. Table 6 contains the breakdown of the themes addressing the third research question. Table 7 contains the breakdown of themes per participant who experienced or mentioned them. 
Table 7: Breakdown of Themes Per Participant.

\begin{tabular}{|c|c|c|c|c|c|c|c|c|c|c|c|}
\hline & $\mathrm{PW}_{1}$ & $\mathrm{PW}_{2}$ & $\mathrm{PW}_{3}$ & $\mathrm{PW}_{4}$ & $\mathrm{PW}_{5}$ & $\mathrm{PW}_{6}$ & $\mathrm{PW}_{7}$ & $\mathrm{PW}_{8}$ & $\mathrm{PW}_{9}$ & $\mathrm{PW}_{10}$ & Frequency\% \\
\hline \multicolumn{12}{|c|}{ RQ\#3: How does perceived resilience improve the overall physical and mental health levels of professional women because of workplace bullying? } \\
\hline \multicolumn{12}{|c|}{ Major Theme 4: Support Systems } \\
\hline Support Systems & $\mathrm{X}$ & $\mathrm{X}$ & $\mathrm{X}$ & & $\mathrm{X}$ & $\mathrm{x}$ & $\mathrm{X}$ & $\mathrm{X}$ & $\mathrm{X}$ & $\mathrm{X}$ & $100 \%$ \\
\hline $\begin{array}{l}\text { Practicing proper exercise and } \\
\text { diet }\end{array}$ & & $\mathrm{X}$ & $\mathrm{X}$ & & $\mathrm{x}$ & $\mathrm{x}$ & & & & $\mathrm{x}$ & $50 \%$ \\
\hline Thinking positive & $\mathrm{x}$ & $\mathrm{X}$ & & & & & $\mathrm{x}$ & $\mathrm{x}$ & & $\mathrm{x}$ & $50 \%$ \\
\hline $\begin{array}{l}\text { Having family and friend } \\
\text { support }\end{array}$ & & & $\mathrm{X}$ & & $\mathrm{x}$ & $\mathrm{x}$ & $\mathrm{x}$ & $\mathrm{x}$ & $\mathrm{X}$ & & $60 \%$ \\
\hline $\begin{array}{c}\text { Seeking outside assistance and } \\
\text { support }\end{array}$ & $\mathrm{X}$ & & $\mathrm{X}$ & & $\mathrm{x}$ & $\mathrm{X}$ & $\mathrm{X}$ & & $\mathrm{X}$ & & $60 \%$ \\
\hline Leaving the workplace & & & & $\mathrm{X}$ & & & & & $\mathrm{X}$ & & $20 \%$ \\
\hline Having a strong faith & $\mathrm{X}$ & $\mathrm{x}$ & & & $\mathrm{x}$ & $\mathrm{x}$ & $\mathrm{X}$ & $\mathrm{x}$ & $\mathrm{X}$ & & $70 \%$ \\
\hline Being stressed & $\mathrm{x}$ & $\mathrm{x}$ & $\mathrm{X}$ & & $\mathrm{x}$ & $\mathrm{x}$ & $\mathrm{x}$ & $\mathrm{x}$ & $\mathrm{x}$ & $\mathrm{x}$ & $90 \%$ \\
\hline Affecting concentration & & & & & $\mathrm{x}$ & & $\mathrm{x}$ & & $\mathrm{x}$ & $\mathrm{x}$ & $40 \%$ \\
\hline Affecting confidence & & $\mathrm{x}$ & & & $\mathrm{X}$ & & & $\mathrm{X}$ & & $\mathrm{X}$ & $40 \%$ \\
\hline
\end{tabular}

The fourth and last major theme that emerged was the support systems that developed the resilience of the participants further. In this major theme or experience, majority of the participants found success and improvement through their different support systems. The major theme had seven underlying interconnected sub-themes, which are presented below.

The first subtheme was having a strong faith, which was shared by seven of the 10 participants or $70 \%$ of the sample. $\mathrm{PW}_{1}$ explained that her strong faith aided her in dealing with the constant bullying and workplace harassment she had to experience and endure. She highlighted that without her faith, she would not have endured and survived the bullying: It all boils down to faith and, you know, your truth, you know, and your ethics. You know, do what what's right. I said if it wasn't for my faith, I wouldn't be here, you know. Well, not sane anyway because I learned through it. I learned to persevere through it. It's been long suffering.

The second subtheme that emerged was having family and friend support, which was shared by six participants. $\mathrm{PW}_{8}$ shared that aside from her faith, she has friends, families, and mentors who are always available to listen and guide her in managing her personal and work issues. Having this network allowed her to adjust and be resilient along the process: Prayer for strength, understand how to cope and how to persevere in the face of adversity and then, also, friends and family who could be sounding board, mentors, other females who have .You know, in the same industry who's been at similar situations. Then, also, just learning. I know that this doesn't sound good but learning not to be a team member, team player, because when I would stand on my own and being independent and do my own fact-finding and my own research and independently come to the conclusion or the work product on my own, then, I didn't have to worry that it was tainted or off-kilter.

Those are some of the things that I was able to do.

The third subtheme of seeking outside assistance and support emerged as again shared by six participants. $\mathrm{PW}_{3}$ believed that she had a strong mechanism and support in going through the bullying at her workplace. She received outside assistance and support where they all responded positively and aided her in dealing with her personal and professional needs and issues: My leadership, my HR leadership, my initial threat was very responsive, very supportive. In fact, when the latest go-round occurred, she came in to speak with the District Attorney because she could. They said, "Listen, I can't have my people not do their job because of your attorney, you've got to do something." She came in and spoke to her, she spoke to the division.

The council. She was very responsive when she was away. When I told her, what was going on and I had been keeping her in the loop but once I did the actual letter, that's when she really said, "Hey, you've put up with this too long, I don't know how you've put up with it as long as you did." She was immediately responsive ... I had a good support mechanism that I was able to talk to and a couple Senior Managers that were very responsive when I needed to talk with them.

The fourth subtheme was practicing proper exercise and diet, as indicated by five of the 10 participants. $\mathrm{PW}_{3}$ added both in the interview and from the researcher's notes that maintaining physical fitness by working out aided her resilience in dealing with her negative issues at work: I think maintaining physical fitness. Working out, particularly at home. I have, up until the last maybe 5 or 6 years, I always worked out. I have other issues. I have done Karate. I'm 63 and I'm a Black belt, so I work out.

The fifth subtheme was by thinking positively, as stated by another five participants. $\mathrm{PW}_{2}$ echoed how resilience allowed her to think positive and continue through her day-to-day life amidst the bullying received and experienced at work: Resilience is key for daily maintenance. Resilience is huge. Resilience bounces you back from life. I think its age. Sometimes you don't back bounce as quickly as when you were younger. It also depends on how folks define resilience, but I think in your day-to-day life, resilience is important to keep going. 
The sixth subtheme that emerged was the result of leaving the workplace. The subtheme received two occurrences. $\mathrm{PW}_{4}$ again explained that although she considered herself mentally and physically resilient, she had no choice but to leave the workplace: Yeah, basically the way it stopped is I'm no longer there. That was the long and short of it. I don't think she would have changed. I don't think she was at all aware of how all over the place she was. Because it's funny that after I left, the young lady who was the admin was still there. As she brought new people in, she would tell them how great I was and how great our relationship was. It was so far from the truth that it's ridiculous, so I don't know. It was weird. I don't think she ever would have changed, though. The RAW Scale [46] measured individual workplace resilience.

Seven subscale components contributed to the participant's overall workplace resilience. The seven components of the RAW Scale included the different values and behaviors of the participants in managing their stress from the bullying experienced.

1) Living Authentically knowing and holding onto personal values, deploying your strengths and having a good level of emotional awareness and regulation

2) Finding Your Calling-Seeking work that has purpose, a sense of belonging and a fit with core values and beliefs

3) Maintaining Perspective-Having the capacity to reframe setbacks, maintain a solution-focus and manage negativity

4) Managing Stress-Employing work and life routines that help manage everyday stressors, maintain work-life balance and ensure time for relaxation

5) Interacting Cooperatively Seeking feedback, advice and support and providing support to others

6) Staying Healthy Maintaining a good level of physical fitness and a healthy diet

7) Building Networks-Developing and maintaining personal support networks

Each RAW Scale [46] item was measured using a Likert scale format with the response options ranging from Strongly Disagree (0); Disagree (1);Somewhat Disagree (2); Neither Agree nor Disagree (3); Somewhat Agree (4); Agree (5); and Strongly Agree (6).

The scores (total and subscales) from a 0-100 score was achieved by a general formula.

The first subscale Living Authentically measured the personal values, strengths, and level of emotional awareness and regulation, and how well these are being used in a workplace environment for each participant. The results revealed that $60 \%$ of the participants achieved a very high or high score as the professional women felt that they could leverage from their strengths and manage their emotions in the workplace, despite the adversity they faced. $\mathrm{PW}_{8}$ shared that there was distrust within the organization; and that there was a significant amount of passive-aggressive bullying where information was being withheld, creating unfavorable situations, which caused her to be "set up for failure."

The second subscale, Finding Your Calling, measured the participant's sense of value and belonging and determined whether they felt a connection in the workplace. The results found that $20 \%$ of the professional women felt although they experienced workplace bullying, they continued to have a sense of connection. Conversely, $60 \%$ of the professional women felt that they were not valued enough in their organizations, and $20 \%$ of the professional women had a significant degree of job dissatisfaction and shared that there was a lack of meaning and/or purpose that they could relate to in the workplace. In fact, $\mathrm{PW}_{2}$ stated, "I am basically just an administrator, paid assistant, not allowed to do my job; and I was told that I don't have a place in that office."

The third subscale, Maintaining Perspective measured individual optimism, remaining focused on solutions with respect to the problems, while buffering the negativity that can be consuming in the workplace. These results revealed that $60 \%$ of the participants achieved high scores as to how they perceived or interpreted the setbacks in the workplace. They appeared to have an optimistic outlook, not focusing on the problem, but finding solutions to move forward. $\mathrm{PW}_{7}$ shared that a coworker would feed her information that would oftentimes be incorrect or not according to the policies and regulations. Rather than continue to get into a confrontation with the coworker, she would call or go directly to the source for the information. Following up on the information she was fed by the co-worker caused "significant conflict and consternation all the time at the office."

The fourth subscale, Managing Stress looked at the work-life balance of participants and measured how effective they were in managing both life and work stressors. The results indicated that $90 \%$ of the participants were able to manage stress in the workplace and that their work-life balance was average. $\mathrm{PW}_{1}$ stated that, "being able to manage everyday stress from the job and home life is critical to relax and unwind and to maintain both a healthy lifestyle and resilience."

The fifth subscale Interacting Cooperatively measured the participant's performance in the workplace. This subscale determined if the participant sought feedback, based on their performance, and whether they were willing to seek support if needed and/or if they were willing to provide support to others in the workplace. From these results, $70 \%$ of the participants had an average to high score in which they sought feedback and support from other coworkers to perform their job more effectively. Additionally, the participants were readily willing to assist and give support to fellow coworkers. Conversely, $30 \%$ of the participants felt that the bullying behavior eroded their performance and was hesitant to seek or provide co-worker assistance because of their experiences.

The sixth subscale, Staying Healthy measured the participant's individual physical fitness and diet levels. Establishing routines to maintain a healthy fitness level and eating right despite the work 
pressures are helpful so that individuals have enough energy to get through the workday. With that, $60 \%$ of the professional women maintained a healthy and balanced lifestyle.

The last subscale, Building Networks measured the participant's support network. This subscale determined if personal and professional support networks were available to draw on and to assist with job and life matters that may have an impact on their individual work performance. These results showed that 3 of the 6 participants had a high or very high support network of which they could turn to for support. Moreover, 2 of the 6 felt that they did not have a personal or professional support system that they could draw on for assistance in the workplace or professional life. Overall, $70 \%$ of the professional women had average individual workplace resilience levels, while $30 \%$ scored below average resilience levels.

The SF12v2, Your Health and Well-Being Survey [45] analyzed the 10 participants' physical and mental health and well-being. It comprised of the Physical Component (PCS) and the Mental Component (MCS) with eight subcomponents including: 1) Physical Functioning (PF); 2) Role Physical (RF); 3) General Health (GH); 4) Bodily Pain; 5) Vitality (VT); 6) Social Functioning; 7) Role Emotional; and 8) Mental Health. The PCS components include PF, $\mathrm{RP}, \mathrm{BP}$, and GH, while the MCS components are VT, SF, RE, and MH. Based on the results of the survey, $50 \%$ of the participants scored an average rating, while $30 \%$ scored an above to very much above average, and $20 \%$ below average for their physical health level. Additionally, $60 \%$ of the participants scored an above average to average rating, while $40 \%$ scored below average to very much below average for their mental health levels.

\section{Findings}

From the qualitative thematic analyses of the interviews and observations, four major themes emerged, which all addressed the three research questions of the study. Workplace bullying primarily consisted of negative actions and treatments. Participants shared that the negative actions and treatments included the following: being humiliated, feeling embarrassed, hearing disparaging remarks, being criticized, receiving bad evaluation and no promotion, feeling belittled, feeling antagonized, being withheld of information, having no communication with coworkers, being yelled or screamed at, and feeling threatened.

The study also found that some of the participants experienced the negative consequences of bullying by either quitting, being fired, or being transferred out of their current position. From the analyses, participants indicated that the resilience for them mainly stemmed from talking with others and relying heavily on faith. Given the gravity of the effects of workplace bullying, participants have discovered how much bullying had a negative impact on their overall health as well. They shared that they observed the following effects: being stressed, having anxiety, experiencing lack of sleep, experiencing headaches and panic attacks, affecting their overall concentration, affecting their confidence, and having depression.

Finally, the resilience theory [51] was again emphasized, wherein the key aspects for the professional women were their support systems. For them, their support systems included having strong faith, having the support of their families and friends, seeking outside assistance, practicing proper exercise and diet, thinking positively, and even leaving the workplace. From a quantitative methodology perspective, it was discovered that the participants mostly reported just an average degree of resilience and a below average to average physical and mental health wellness.

\section{Limitations}

In addition to the small sample size, the main limitation of this study was the employment of the participants' perceptions and different bullying experiences in the interviews. Given the direct use of the participants' perceptions, their responses might have been limited and controlled. Additionally, the design of this study, as a result of the four data sources: open-ended interviews, researcher notes, and the two structured questionnaires, the researcher depended on the integrity of the participants, and hoped that each participant provided honest responses to each of the questions posed.

Due to the participants beingwell-educated female professionals and only coming from the National Capital Region of Washington, D.C, an additional limitation was that this study did not fully represent the demographic, geographic, nor professional diversity that otherwise may be found in other parts of the United States. The participant's perceptions and experiences were all considered and coded in addressing the research questions of the study. This was performed in order to maximize the data; and include the most common experiences of women faced with workplace bullying that could also be applicable for many professional women in the country. A final limitation was that triangulation was not achieved. Data sources were reported separately; therefore, no patterns or trends were identified across sources of data.

\section{Implications for research and practice}

This study highlighted the applicability of resilience theory in managing workplace bullying of professional women. Both the interviewed women and the literature provided evidence on ways in which the resilience theory could be employed as support for women who were dealing with the negative effects of workplace bullying. Based on the findings, the need for the resilience theory was strengthened as the participants specified how much resilience helped them in their battle with workplace bullying. For the participants, resilience validated the support that they were receiving from their families, relatives, friends, and from individuals who were close to them. The findings inferred that the resilience theory should be acclimatized by the organizations and companies to increase the sturdiness of their employees in dealing with the negative consequences of workplace bullying.

The familiarization of the organizations to the effectiveness of resilience, as well as the motion for their employees to practice and apply resilience in their everyday difficulties, issues, and most importantly on workplace bullying, should raise the current conditions of the professional women who were dealing with workplace abuses and harassments. As for the practical 
implications of the study, based on the findings, future researchers, as well as the organizations and their employees experiencing workplace bullying, could benefit from the narratives, perceptions, and experiences of the professional women interviewed. Future researchers could utilize the themes developed and the results of the surveys to demonstrate ways in which much workplace bullying affected the personal and professional state of the victims.

Further, the authenticity of the findings on the effects of workplace bullying and ways in which resilience could be used as a strategy to cope with it, also should allow future researchers to use the content to strengthen their exploration on the connectedness of the resilience theory to workplace bullying for women professionals. As for the victims of workplace bullying, they could gain insight from the narratives of the other victims interviewed in the study and acquire the proper knowledge and capabilities to use resilience as their weapon in dealing with workplace bullying. Meanwhile, organizations could step forward and gain an understanding from the findings that resilience could be one of the major solutions to the issue of workplace bullying in their organizations or companies. For the future implications of the study, it was expected that, from the findings, more women and their organizations should be made aware of workplace bullying, even at the most minimal symptoms and stages of the said act. The findings of the study should create awareness that professional women must be given the proper attention and guidance from their organizations to endure the negative impacts of bullying.

Finally, resilience should diminish the reported negative experiences of the women in this study and provide them with the strength to bear the consequences of workplace bullying. With the new-found positive effects of resilience as a coping strategy, victims in the future should already could fight workplace bullying and be as effective and productive as they could be to benefit their personal and professional lives, as well as their organizations in general.

\section{Conclusion}

The issue of workplace bullying has gained significance over the past two decades given the negative impact that it brings to the victim, the bully or the abusers, and the company. As both the workers and organizations are affected, workplace bullying has an increased tendency of reducing the productivity and efficiency of the workers; in the end, it can result to a financial loss for the organization [10,52]. According to the literature, women are bullied at much higher rates and more often compared to men [7], so examining resilience as a useful coping strategy, when dealing with bullying in the workplace, was essential to help improve the overall well-being of professional women who were or have experienced workplace bullying.

Based on the analysis and results of the study, the leaders of organizations and companies must search for methods or strategies that can aid in uplifting their employees who are experiencing bullying within their workplace environment. This research study promoted the need for more attention and awareness on how resilience could be used as a coping strategy to help address workplace bullying of professional women. Using the interviews, observation notes, and two survey resources, this study explored the effectiveness of resilience on the personal and professional coping strategies of the women. Furthermore, the qualitative thematic analysis of the interviews and observations, which established themes and allowed for the interpretations of the surveys to be strengthened. From the analyses of the interviews and observations, it was found that the majority of the interviewed professional women perceived that indeed, race, gender, and age were factors of workplace bullying; they were experiencing negative actions and treatment and that some were still experiencing the consequences of bullying. The perceived resilience was considered an effective coping strategy, as participants found a significant, negative impact on their health.

Lastly, the interviewed participants indicated that the major factor of resilience was having strong support systems from their family, relatives, and friends. Meanwhile, from the surveys, the interviewed professional women reported just an "average" degree of resilience and an "average to below average" physical and mental health operative due to bullying. These findings pointed toward the need to encourage organizations and companies to consider resilience as one of the practices to be promoted in helping their women employees in managing workplace bullying.

Workplace bullying is recognized as a serious threat to the health and well-being of employees [2]. Working women should be able to work and perform their duties in a workplace environment that is free from bullying, harassment, or any other unacceptable behavior [53]. Using the resilience theory [51], [54-57] as the framework, this study introduced an awareness that was needed to understand what it meant to be resilient when faced with an adversity such as workplace bullying. This is important, while recognizing that there are better coping strategies, which can usher professional women to increased confidence and overall well-being by enabling them to be stronger and more confident in the workforce.

The findings from this study suggests that exploring resilience as a coping strategy would not only benefit professional women, but also men, and organizations when dealing with workplace bullying behaviors. Additionally, the findings provided a descriptive case study on resilience, when used as a coping strategy for workplace bullying, which offered the reader insight that determined the need to explore other useful coping strategies, which could help the workplace environment become more wholesome. Further, the information uncovered in this study, should encourage others to explore resilience as a coping strategy for professional women in the workforce who have or are experiencing workplace bullying.

\section{Acknowledgement}

None.

\section{Conflict of Interest}

Author declare no conflict of interest. 


\section{References}

1. Gholipour A, Sanjari S, Bod M, Kozekanan S (2011) Organizational bullying and women stress in workplace. International Journal of Business and Management 6(6): 234-241.

2. Høgh A, Mikkelsen EG, Hansen AM, (2011) Individual consequences of workplace bullying/mobbing. In: S Einarsen, H Hoel, D Zapf, CL Cooper (Eds), Workplace bullying: Developments in theory research and practice, pp. 107-128.

3. Einarsen S, Hoel H, Notelaers G (2009) Measuring exposure to bullying and harassment at work: Validity, factors structure and psychometric properties of the Negative Acts Questionnaire-Revised. Work \& Stress 23(1): 24-44.

4. Keashly L, Harvey S (2006) Workplace emotional abuse. In: E. Kelloway J Barling \& J Hurrell (Eds), Handbook of workplace violence. CA, pp. 95120.

5. Keashly L, Jagatic K (2011) North American perspectives on hostile behaviors and bullying at work. In: S Einarsen, H Hoel, D Zapf, C Cooper (Eds), Bullying and harassment in the workplace: Developments in theory, research, and practice. $2^{\text {nd }}$ edn, USA, pp. 41-71.

6. Zapf D, Escartin J, Einarsen S, Hoel H, Vartia M (2011) Empirical findings on prevalence and risk groups of bullying in the workplace. In: S Einarsen, H Hoel, D Zapf, C Cooper (Eds), Bullying and harassment in the workplace: Developments in theory, research, and practice. $2^{\text {nd }} e d n$, pp. 75-106.

7. Workplace Bullying Institute (2014) WBI US workplace bullying survey.

8. Olweus D (1978) Aggression in the schools: Bullies and whipping boys. Washington DC: Hemisphere Press, USA.

9. Samnani A, Singh P (2012) 20 years of workplace bullying research: A review of the antecedents and consequences of bullying in the workplace. Aggression and Violent Behavior 17(6): 581-589.

10. Branch S, Ramsay S, Barker M (2012) Workplace bullying, mobbing and general harassment: A review. International Journal of Management Reviews 15(3): 280-299.

11. Windle G, Bennett K, Noyes J (2011) A methodological review of resilience measurement scales. Health Qual Life Outcomes 9: 8.

12. MacIntosh J (2012) Workplace bullying influences women's engagement in the workforce. Issues Ment Health Nurs 33(11): 762-768.

13. Appelbaum SH, Semerjian G, Mohan K (2012) Workplace bullying: Consequences, causes and controls (part one). Industrial and Commercial Training 44(4): 203-210.

14. Glambek M, Matthiesen SB, Hetland J, Einarsen S (2014) Workplace bullying as an antecedent to job insecurity and intention to leave: A 6-month prospective study. Human Resource Management Journal 24(3): 255-268.

15. McTernan WP, Dollard MF, LaMontagne AD (2013) Depression in the workplace: An economic cost analysis of depression-related productivity loss attributable to job strain and bullying. Work \& Stress 27(4): 321338.

16. Wilson BL, Diedrich A, Phelps CL, Choi M (2011) Bullies at work: The impact of horizontal hostility in the hospital setting and intent to leave. Journal of Nursing Administration 41(11): 453-458.

17. Lewis S (2006) Recognition of workplace bullying: A qualitative study of women targets in the public sector. Journal of Community \& Applied Social Psychology 16(2): 119-135.

18. Berthelsen M, Skogstad A, Lau B, Einarsen S (2011) Do they stay, or do they go? A longitudinal study of intentions to leave and exclusion from working life among targets of workplace bullying. International Journal of Manpower 32(2): 178-193.

19. Garima M, Kiran UV (2014) Impact of marital status on mental health of working women. Journal of Medical Science and Clinical Research 2(10): 2594-2605.

20. Sloan LM, Matyok T, Schmitz CL, Glenda F Lester (2010) A story to tell: Bullying and mobbing in the workplace. International Journal of Business and Social Science 1(3): 87-97.
21. Mikkelsen EG, Einarsen S (2001) Bullying in Danish work-life: Prevalence and health correlates. European Journal of Work and Organizational Psychology 10(4): 393-413.

22. Leymann H (1990) Mobbing and psychological terrorism at workplaces. Violence Vict 2(5): 119-126.

23. Niedl K (1996) Mobbing and well-being: Economic and personnel development implications. European Journal of Work and Organizational Psychology 5(2):239-249.

24. Björkqvist K, Österman K, Hjelt-Bäck M (1994) Aggression among university employees. Aggressive Behavior 3(20): 173-184.

25. Groeblinghoff G, Becker M (1996) A case study of mobbing and the clinical treatment of mobbing victims. European Journal of Work and Organizational Psychology 5(2): 277- 294.

26. Leymann, H, Gustaffson A (1996) Mobbing at work and the development of post-traumatic stress disorder. European Journal of Work and Organizational Psychology 5(2): 251- 275.

27. Mikkelsen EG, Einarsen S (2002) Basic assumptions and symptoms of post-traumatic stress among victims of bullying at work. European Journal of Work and Organizational Psychology 11(1): 87-111.

28. Nasr Esfahani A, Shahbazi G (2014) Workplace bullying in nursing: The case of Azerbaijan Province, Iran. Iran J Nurs Midwifery res 19(4): 409415.

29. Maidaniuc-Chirilă T (2015) The mediation role of resilience on the relationship between workplace bullying and Romanian employees' physical strain. 48: 120-133.

30. Sauer P (2013) Does resilience mediate the effects of bullying in nurses? (Doctoral dissertation). The University of North Carolina at Greensboro.

31. Lian S, Tam CL (2014) Work stress, coping strategies and resilience: A study among working females. Asian Social Science 10(12): 41-51.

32. Einarsen S, Raknes BI, Matthiesen SB (1994) Bullying and harassment at work and their relationships to work environment quality: An exploratory study. European Work and Organizational Psychologist 4(4): 381-401.

33. Monks CP, Smith PK, Naylor P, Ireland JL, Coyne I (2009) Bullying in different contexts: Commonalities, differences and the role of theory. Aggression and Violent Behavior: A Review Journal 14(2):146-156.

34. Einarsen S, Hoel H, Zapf D, Cooper CL, (2011) The concept of bullying and harassment at work: The European tradition. In: Bullying and harassment in the workplace: Developments in theory, research, and practice. pp. 3-40.

35. Rayner C, Cooper CL (2006) Workplace bullying. In: KE Kelloway, J Barling JJ, Hurrell Jr (Eds), Handbook of workplace violence. pp. 121145.

36. Rayner C, Keashly L (2005) Bullying at work: Perspectives from Britain and North America. In: S Fox, PE Spector (Eds), Counterproductive work behaviors: Investigations of actors and targets. pp. 271-296.

37. Cunniff L, Mostert K (2012) Prevalence of workplace bullying of South African employees. S A Journal of Human Resource Management 10(1): $1-15$.

38. Escartin J, Rodriquez-Carballeira A, Zapf D, Porrúa C, Martin-Peña J (2009) Perceived severity of various bullying behaviors at work and the relevance of exposure to bullying. Work \& Stress 23(3): 191-205.

39. Leo L, Reid R, Geldenhuys M, Gobind J (2014) The inferences of gender in workplace bullying: A conceptual analysis. Gender \& Behaviour 12(3): 6059-6069.

40. Gardner D, Bentley T, Catley B, Cooper-Thomas H, O’Driscoll M, et al. (2013) Ethnicity, workplace bullying, social support and psychological strain in Aotearoa/New Zealand. New Zealand Journal of Psychology 42(2): 84-91.

41. Cortina LM, Magley VJ, Williams JH, Langhout RD (2002) Incivility in the workplace: Incidence and impact. J Occup Health Psychol 6(1): 64- 80.

42. Tehrani N (2004) Bullying: A source of chronic post-traumatic stress? British Journal of Guidance \& Counseling 32(3): 357-366. 
43. Van Heugten K (2010) Bullying of social workers: Outcomes of a grounded study into impacts and interventions. British Journal of Social Work 40(2): 638-655.

44. Hofer MA (2006) Evolutionary basis of adaptation in resilience and vulnerability: Response to Cicchetti and Blender. Ann N Y Acad Sci 1094:259-262.

45. Maruish ME (2012) User's manual for the SF- $12 v_{2}$ Health Survey $3^{\text {rd }}$ edn. Lincoln, RI: Quality Metric Incorporated.

46. McEwen, K, Winwood PC (2011) Resilience at Work (R@W) Scale. Samford Valley, Australia: Australian Academic Press.

47. Winwood, PC, Colon R, McEwen K (2013) A practical measure of workplace resilience: Developing the resilience at work scale. Occup Environ Med 55(10): 1205-1212.

48. Attride-Stirling J (2001) Thematic networks: An analytic tool for qualitative research. Qualitative Research 1(3): 385-405.

49. Braun V, Clarke V (2006) Using thematic analysis in psychology. Qualitative Research in Psychology 3(2): 77-101.

50. Yin RK (2013) Case study research: Design and methods $5^{\text {th }}$ edn. Thousand Oaks, CA: Sage.

51. Garmezy N (1974) The study of competence in children at risk for severe psychopathology. In: EJ Anthony \& C Koupernik (Eds), The child in his family: Children at psychiatric risk, USA, pp. 77-97.
52. Bradbury J, Hutchinson M (2015) Workplace bullying: Modelling construct validity in an Australian public sector workforce. Journal of Empirical Studies 2(1): 1-16.

53. Stagg S, Sheridan D (2010) Effectiveness of bullying and violence prevention programs: A systematic review. AAOHN J 58(10): 419-424.

54. Garmezy N (1993) Children in poverty: Resilience despite risk. Psychiatry 56(1): 127-136.

55. Garmezy N, Masten A, Tellegen A (1984) The study of stress and competence in children: A building block for developmental psychopathology. Child Dev 55(1): 97-111.

56. Rutter M (1985) Resilience in the face of adversity: Protective factors and resistance to psychiatric disorder. Br J Psychiatry 147(1): 598-611.

57. Werner EE, (1993) Risk, resilience, and recovery: Perspectives from the Kauai Longitudinal Study. Development and Psychopathology 5(1): 503515.

58. Mealer M, Jones J, Moss M (2012) A qualitative study of resilience and posttraumatic stress disorder in United States ICU nurses. Intensive Care Med 38(9): 1445-1451.

59. Tusaie K, Dyer J (2004) Resilience: A historical review of the construct. Holistic Nursing Pract 18(1): 3-8.

60. Van Heugten K (2013) Resilience as an underexplored outcome of workplace bullying. Qual Health Res 23(3): 291-301. 